\title{
Permanent iodine-125 brachytherapy for patients with progressive or recurrent high- grade gliomas
}

Congxiao Wang', Shifeng Liu', Lijing Peng², Kaixian Zhang ${ }^{3}$, Wei Li' ${ }^{1}$, Hao Zhang ${ }^{1}$, Ying Luan ${ }^{4}$, Peishun Li ${ }^{3}$ and Xiaokun $\mathrm{Hu}^{1 *}$ (D)

\begin{abstract}
Background: The prognosis of patients with progressive or recurrent high-grade gliomas (HGGs) after surgery remains poor. lodine-125 brachytherapy is emerging as a salvage method for the treatment of gliomas. This study aimed to investigate whether permanent iodine-125 brachytherapy could be used as an effective therapeutic method even without radiotherapy and/or chemotherapy for progressive or recurrent HGG after gross total resection.

Methods: Between March 2004 and August 2016, 58 patients with progressive or recurrent HGG after gross total resection were included in this study. Twenty-nine patients underwent radiotherapy and/or chemotherapy and then permanent iodine-125 brachytherapy (SRCl group). Twenty-nine patients underwent permanent iodine-125 brachytherapy alone (SI group). Follow-up was carried out at 1, 3, and 6 months and then at 1, 2, 3, and 5 years after iodine-125 implantation. The median overall survival (OS) and progression-free survival (PFS), procedure-related complications and clinical outcomes were evaluated.

Results: No procedure-related fatal events happened. The temporary morbidity rate was $11.9 \%$. The median OS and PFS for patients in the SI group were 22 and 8 months compared with 21 and 7 months in the SRCl group. No significant differences were found. Age and Karnofsky Performance Status (KPS) were independent prognostic factors for OS. Age, KPS and histology were independent prognostic factors for PFS.

Conclusions: Permanent iodine-125 brachytherapy could be used as an effective therapeutic method even without radiotherapy and/or chemotherapy for progressive or recurrent HGG after gross total resection.
\end{abstract}

Keywords: Progressive or recurrent high-grade gliomas, lodine-125 brachytherapy, Radiotherapy, Chemotherapy

\section{Background}

High-grade gliomas (HGGs) are the most common primary brain tumors, and HGG accounts for approximately $2 \%$ of all cancers and $70-80 \%$ of all brain tumors [1-3]. Gliomas are thought to originate from glial, stem or

\footnotetext{
* Correspondence: huxiaokun770@163.com

'Department of the Interventional Medical Center, the Affiliated Hospital of Qingdao University, \#1677 Wutaishan Road, Qingdao 266000, Shandong, China

Full list of author information is available at the end of the article
}

neuronal precursor cells. According to the WHO criteria, gliomas are histologically classified into four different grades (grade I to grade IV), and grade III and grade IV tumors are the so-called high-grade or malignant gliomas [4]. HGG is one of the most devastating human diseases due to its diffusely infiltrating spread characteristics [5]. Primary tumor resection is the first-line therapy for HGG [4]. However, the prognosis of patients remains poor regardless of aggressive treatment, and most patients die due to the disease or related complications, with a median

(C) The Author(s). 2020 Open Access This article is licensed under a Creative Commons Attribution 4.0 International License, which permits use, sharing, adaptation, distribution and reproduction in any medium or format, as long as you give appropriate credit to the original author(s) and the source, provide a link to the Creative Commons licence, and indicate if changes were made. The images or other third party material in this article are included in the article's Creative Commons licence, unless indicated otherwise in a credit line to the material. If material is not included in the article's Creative Commons licence and your intended use is not permitted by statutory regulation or exceeds the permitted use, you will need to obtain permission directly from the copyright holder. To view a copy of this licence, visit http://creativecommons.org/licenses/by/4.0/ The Creative Commons Public Domain Dedication waiver (http://creativecommons.org/publicdomain/zero/1.0/) applies to the data made available in this article, unless otherwise stated in a credit line to the data. 
survival of 9-12 months [4, 6]. Owing to the diffuse and infiltrative characteristics of the tumor, malignant gliomas often recur even when gross total resection has been carried out [4]. The treatment for progressive or recurrent HGG remains a controversial subject. For patients with progressive or recurrent HGG, repeated surgery is usually unfeasible, and radiotherapy and/or chemotherapy are usually chosen but are often not effective options; moreover, their safety also remains a question [7].

Iodine-125 brachytherapy is emerging as a promising therapeutic method for gliomas that promotes the survival of patients $[6,8]$. The implantation of iodine- 125 seeds is a safe, accurate and effective treatment method with minimal invasion and a consecutive low-dose rate of radiation that places the seeds within the tumor $[6,9]$, which is different from external beam radiotherapy (EBRT). Recently, iodine- 125 brachytherapy has been suggested to be an effective salvage therapy for patients with progressive or recurrent gliomas [7, 10]; however, whether radiotherapy and chemotherapy before iodine- 125 brachytherapy is necessary has not been explored.

In this study, we aimed to investigate whether permanent iodine-125 brachytherapy could be used as an effective therapeutic method even without radiotherapy and/or chemotherapy for progressive or recurrent HGG after gross total resection. The advantages will also be explored.

\section{Methods}

\section{Patient criteria}

This study retrospectively analyzed patients from the database of the Affiliated Hospital of Qingdao University in China from Mar. 2004 to Jun. 2017. The study was approved by the Institutional Ethics Review Boards of the Affiliated Hospital of Qingdao University with the requirement of informed consent waived (Reference number: QYFY WZLL 25802). Patients who met the following criteria were included in our study: (a) 16 years of age or older; (b) histologic diagnosis of WHO grade III or IV glioma; (c) contrast-enhancing tumor; (d) relapse of glioma after gross total tumor resection; and (e) availability of adequate laboratory examination information, including hematologic parameters, clotting, hepatic and renal function, etc. Patients were excluded if the tumor involved the brain stem or ependymal surface.

The 58 patients included in this study were divided into two groups. The SI group (surgery+ iodine-125 brachytherapy, $n=29$ ) included patients with progressive or recurrent HGG after gross total resection who received permanent iodine-125 brachytherapy. The SRCI group (surgery+ radiotherapy and/or chemotherapy+ iodine-125 brachytherapy, $n=29$ ) included patients with progressive or recurrent HGG after gross total resection who received radiotherapy and/or chemotherapy; when relapse was observed, permanent iodine-125 brachytherapy was given.

\section{Study outcomes}

The outcomes observed were median overall survival (OS) and median progression-free survival (PFS). OS was defined as the time from the diagnosis of HGG to the date of death or the last follow-up. PFS was defined as the time from the implantation of iodine- 125 seeds to the diagnosis of tumor recurrence or progression. Additionally, univariate analysis $(\log$-rank test, $P<0.05)$ and multivariate analysis (Cox proportional hazards model, $\mathrm{P}<0.05)$ were performed to determine the possible prognostic factors for OS and PFS.

\section{Treatment plans}

All patients with progressive and recurrent HGG had previously underwent gross total resection. For iodine125 seed implantation, a computerized treatment planning system (TPS; Beijing Astro Technology Ltd. Co., Beijing, China) was used. Based on computed tomography $(\mathrm{CT})$ or magnetic resonance imaging (MRI) images before implantation, the prescribed dose (PD) of $100-150$ Gy was administered. The planning target volume (PTV) consisted of the region of the gross target volume plus a $10 \mathrm{~mm}$ margin in all three dimensions defined by CT scan. The insertion site, path, and direction of the needles were decided, and seeds were designed 5$10 \mathrm{~mm}$ apart. The isodose curve distribution and dose volume histogram (DVH) were plotted, and the D90, D100, V200, V100, and V90 were calculated. After the surgery, the TPS was used to confirm the rationality of the seed distribution.

\section{lodine-125 implantation}

The patients were securely positioned on the CT scan bed with a negative pressure vacuum pad. They were locally anesthetized with $2 \%$ lidocaine, and an incision was made with a blade on the scalp. Holes with diameters of $2 \mathrm{~mm}-4 \mathrm{~mm}$ were made with an electric cranial drill. A dynamic CT scan was carried out before the implantation to show the boundary of the gliomas. Iodine- 125 seeds (diameter of $0.8 \mathrm{~mm}$, length of $4.5 \mathrm{~mm}$, half value of $0.025 \mathrm{~mm}$ in lead, half-life of 59.4 days; Model 7711, Beijing Atom and High Technique Industries, Inc., Beijing, China) were implanted with flat needles; the path of the needles and the distribution of the seeds during the operation were dynamically monitored and rectified with intraoperative CT scans, and dosimetric verification was performed with the TPS during the operation to help with the implantation. The galea aponeurosis and the scalp were sutured after implantation to prevent the leakage of cerebrospinal fluid. The whole surgery lasted for $1-2 \mathrm{~h}$ altogether. After implantation, 
Table 1 Patients and Implantation Characteristics

\begin{tabular}{lllr}
\hline Characteristics & $\mathrm{SI}(\mathrm{n}=29)$ & $\mathrm{SRCl}(\mathrm{n}=29)$ & $\mathrm{p} \mathrm{Value} \mathrm{a}^{\mathrm{a}}$ \\
\hline $\begin{array}{l}\text { Age (yrs) } \\
\quad \text { Median (Range) }\end{array}$ & $46(20-73)$ & $46(16-70)$ & 0.637 \\
Sex & & & \\
$\quad$ Male & $17(58.6)$ & $19(65.5)$ & \\
$\quad$ Female & $12(41.4)$ & $10(34.5)$ & \\
KPS & $22(75.9)$ & & \\
$\quad$ Median (Range) & $80(50-80)$ & $80(50-90)$ & 0.401 \\
$90-100$ & $11(37.9)$ & $8(27.6)$ & \\
$\leq 80$ & $18(62.1)$ & $21(72.4)$ &
\end{tabular}

\section{Extent of Resection}

$\begin{array}{lll}\text { Gross total resection } & 29(100) & 29(100) \\ \text { Partial resection } & 0(0) & 0(0) \\ \text { Biopsy } & 0(0) & 0(0)\end{array}$

\section{ERBT dose (Gy)}

Median (Range)

Adjuvant chemotherapy

Tumor position

$\begin{array}{lll}\text { Frontal lobe } & 6(20.7) & 11(37.9) \\ \text { Occipital lobe } & 1(3.5) & 0(0) \\ \text { Parietal lobe } & 4(13.8) & 0(0) \\ \text { Temporal lobe } & 9(31.0) & 6(20.7) \\ \text { multi-lobe } & 9(31.0) & 12(41.4) \\ \text { Tumor location } & & 13(44.8) \\ \text { Left hemisphere } & 16(55.2) & 16(55.1) \\ \begin{array}{l}\text { Right hemisphere } \\ \text { Both hemisphere }\end{array} & 11(37.9) & 0(0) \\ \text { Tumor Diameter } & 2(6.9) & 10(34.5) \\ \geq 5 \mathrm{~cm} & 12(41.4) & 19(65.5) \\ <5 \mathrm{~cm} & 17(58.6) & 6(20.7) \\ \text { Histology } & & 23(79.3) \\ \text { WHO III } & 7(24.1) & \\ \text { WHO IV } & 22(75.9) & \end{array}$

No. of seeds

$$
\text { Median (Range) }
$$

PD (Gy)

Symptoms prior to implantation

$\begin{array}{lllr}\text { Headace } & 27(93.1) & 27(93.1) & >0.999 \\ \text { Nausea } & 22(75.9) & 18(62.1) & 0.256 \\ \text { Vomit } & 14(48.3) & 12(41.4) & 0.597 \\ \text { Vertigo } & 6(20.7) & 9(31.0) & 0.368 \\ \text { Myodynamic } & & & 0.387 \\ \geq \text { grade 4 } & 22(75.9) & 19(65.5) & \\ \text { < grade 4 } & 7(24.1) & 10(34.5) & \\ \text { Vision } & 6(20.7) & 10(34.5) & 0.240\end{array}$

Table 1 Patients and Implantation Characteristics (Continued)

\begin{tabular}{cllr}
\hline Characteristics & $\mathrm{SI}(\mathrm{n}=29)$ & $\mathrm{SRCI}(\mathrm{n}=29)$ & $\mathrm{p} \mathrm{Value}^{\mathrm{a}}$ \\
\hline Hearing & $5(17.2)$ & $3(10.3)$ & 0.446 \\
Aphasia & $6(20.7)$ & $4(13.8)$ & 0.487 \\
Epilepsy & $22(75.9)$ & $11(37.9)$ & 0.004 \\
Sensory & $3(10.3)$ & $5(17.2)$ & 0.446 \\
\hline
\end{tabular}

Note-Date in parentheses are percentages unless indicated KPS, Karnofsky Perfomance Scale; EBRT, external beam radiotherapy ${ }^{\mathrm{a}} \mathrm{X} 2$ test or Student's t-test tests were used

vital signs were monitored, and the patients were required to be inactive for $24 \mathrm{~h}$ and were routinely treated with dehydration medications for 7-14 days.

\section{Patient evaluation}

The status of the patients was evaluated before the surgery of iodine-125 seed implantation and immediately when they were discharged from the hospital. Complications after implantation were also recorded. The followups were carried out at 1,3 , and 6 months and then at 1 , 2,3 , and 5 years after seed implantation, mainly via telephone interviews. Headache, nausea, vomiting, vertigo, myodynamics, vision, hearing, aphasia, epilepsy and sensory function were evaluated before and after seed implantation. OS and PFS were compared between the two groups. Causes of death were recorded.

\section{Statistical methods}

The last follow-up was on 31 Jul. 2017. The data were analyzed using SPSS (Version 18.0, IBM, NY, USA). Categorical variables are presented as frequencies and percentages, and continuous variables are presented as medians and ranges. The baseline characteristics of the patients in the two groups were compared with $\chi^{2}$ or Fisher exact tests for categorical variables or two-tailed Student's t-test for continuous variables. OS and PFS were calculated with the Kaplan-Meier method. The logrank test was used for the univariate analysis, and all variables with $P \leq 0.1$ or those $(p>0.1)$ thought to be clinically important were included in the multivariate analysis. A Cox proportional hazards model was used for multivariate analysis. $P<0.05$ was considered statistically significant.

\section{Results}

\section{Patient characteristics}

Table 1 shows the baseline characteristics of the 58 patients with progressive or recurrent HGG after gross total resection in this study. All the patients in the SRCI group were treated with EBRT (median, $60 \mathrm{~Gy}$; range, 34-70 Gy). Of the 29 patients in the SRCI group, 11 underwent adjuvant chemotherapy with temozolomide. More patients had epilepsy in the SI group (22 of 29, $75.9 \%$ ) than in the SRCI group (11 of $29,37.9 \%)$. No 
significant differences were found in the other symptoms before seed implantation, such as headache, nausea, vomiting, vertigo, myodynamics, vision, hearing, aphasia and sensory function. The other variables were not significantly different between the two groups.

\section{lodine-125 seed implantation}

Before iodine-125 seed implantation, an implantation plan was made with a computerized TPS. The needle path, seed distribution, isodose curve, and DVH are shown in Fig. 1a-b. After the implantation, the plan was verified, as shown in Fig. 1c-d.

\section{Perioperative mortality and morbidity}

No surgery-related fatal events happened (perioperative mortality rate, $0 \%$ ). The temporary morbidity rate was $11.9 \%$. Cerebral hemorrhage happened in 4 patients (6.8\%), and 3 patients had heavier brain edema (5.1\%). The patients with heavier brain edema improved a few months after the implantation with dehydration treatment, and self-absorption of the cerebral hemorrhage was almost complete approximately 15 days with the conservation treatment.

\section{Survival analysis}

The median OS of the patients was 22.0 months (95\% confidence interval (CI): $14.50-29.50$ months) in the SI group and 21.0 months (95\% CI: 18.89-23.11 months) in the SRCI group. The median PFS of the patients was 8.0 months (95\% CI: $5.47-10.53$ months) in the SI group and 7 months (95\% CI: 4.74-9.26 months) in the SRCI group. No significant differences were found between the two groups in OS $(p=0.751)$ or PFS $(p=0.203)$ (Fig. 2a-b).

One patient lost contact, and the other 57 patients died during our follow-up. Four patients in the SI group survived more than 36 months, with the longest survival time being 187 months. Five patients in the SRCI group

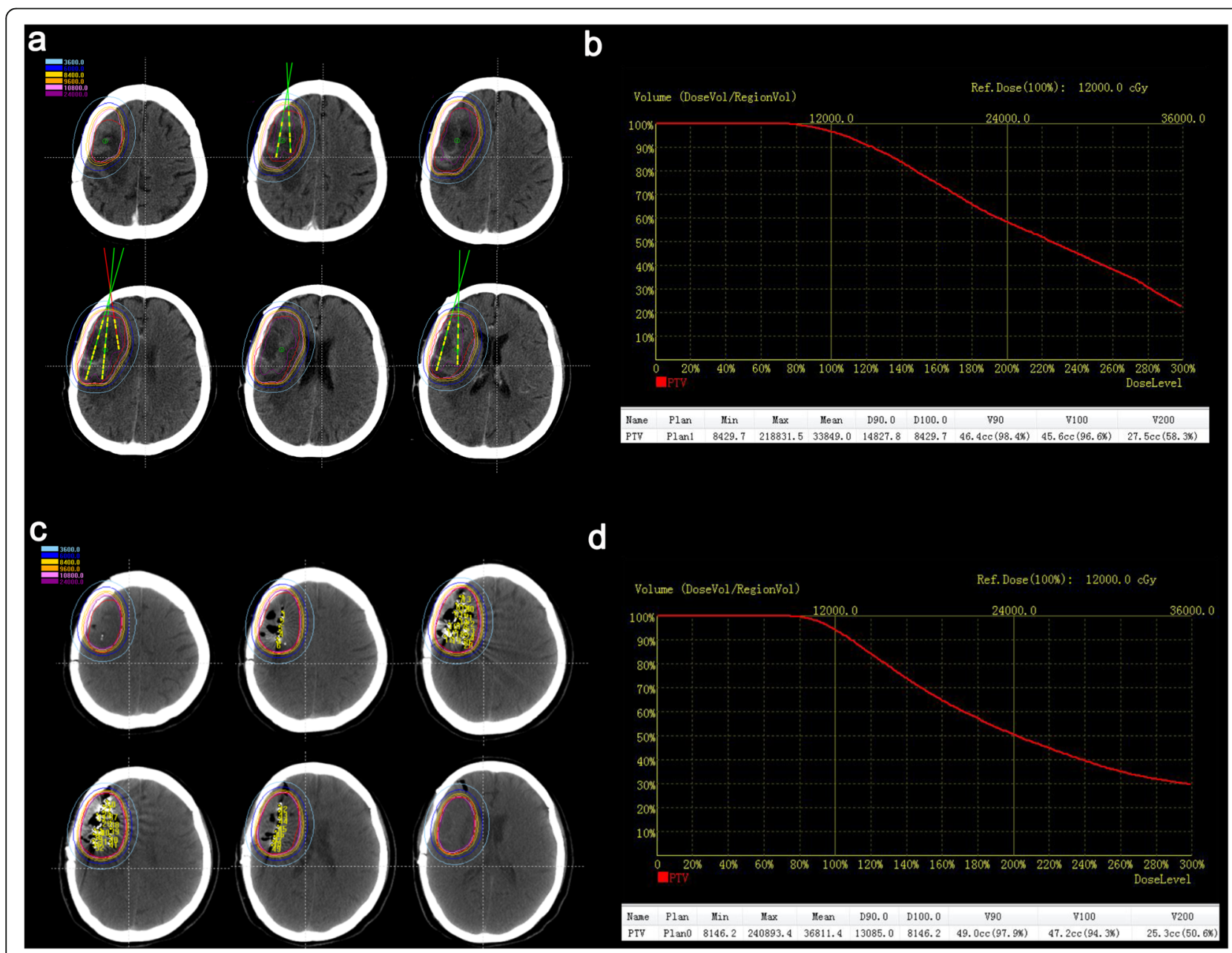

Fig. 1 Treatment planning and verification. (a) The planning target volume (PTV) is outlined with a red line, and the dose distribution is outlined with different colored lines. Additionally, a needle path was designed before the operation with the computerized treatment planning system. (b) Dose volume histogram (DVH) of PTV preoperation. (c) Verification of the dose distribution postsurgery. (d) DVH of PTV postoperation 

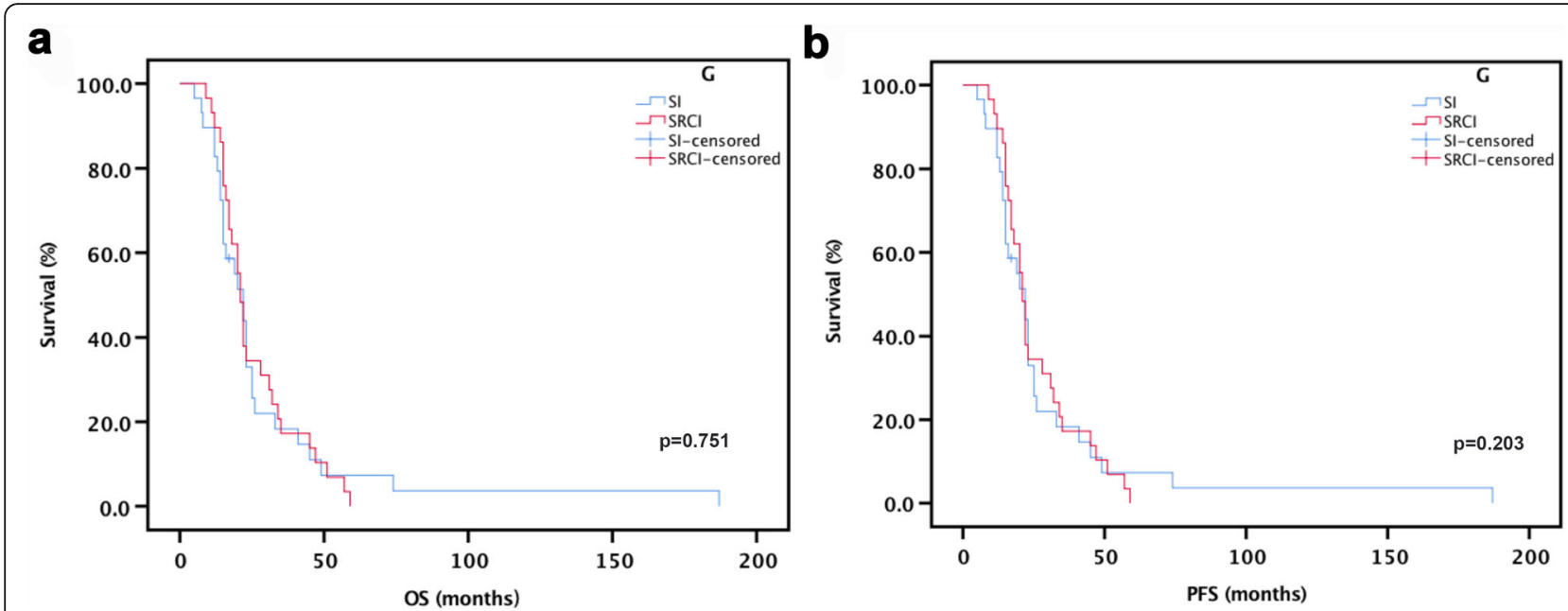

Fig. 2 Kaplan-Meier analysis of OS and PFS (a) The median OS was 22 months in the SI group compared with 21 months in the SRCI group ( $p=0.751$ ). (b) The median PFS was 8 months in the SI group compared with 7 months in the SRCI group $(p=0.203)$

survived more than 36 months, with the longest survival time being 59 months.

\section{Prognostic factors}

To further investigate the factors related to the survival of patients, we first performed univariate analysis of covariates, and the results showed that age and Karnofsky Performance Status (KPS) were significant for OS. Age, KPS, tumor diameter, and nausea were significant for PFS (Table 2). Factors with a $p$ value $\leq 0.1$ and those thought to be clinically significant were included in the multivariate analysis. The results showed that age and KPS were independent prognostic factors for OS. Age, KPS and histology were independent prognostic factors for PFS (Table 3).

\section{Follow-up after lodine-125 implantation}

Quality of life was assessed with KPS at different time points. The mean pretreatment KPS score was 80 (range 50-90) in the SI group and 80 (range 50-90) in the SRCI group. No significant differences were found between the groups $(p=0.401)$. The median KPS scores of patients at the time of discharge from the hospital and those who survived for 1 month, 3 months, 6 months, 1 year, 2 years, and 3 years in the SI group were 80 (range 60-100), 80 (range 40-100), 80 (range 30-100), 80 (range 50-100), 90 (range 60-100), 70 (range 50-90), and 70 (range 50-90), and the median KPS scores of patients at the time of discharge from the hospital and those who survived for 1 month, 3 months, 6 months, 1 year, and 2 years in the SRCI group were 70 (range 40100), 80 (range 40-100), 70 (range 30-100), 70 (range 30-100), 70 (range 50-100), and 70 (range 70-80), respectively. In the SI group, 22 patients died due to brain hernia, 2 patients died due to brain edema, and 5 patients died of unknown causes. In the SRCI group, patients died due to brain hernia ( 20 of 30 patients), brain edema ( 1 of 30 patients), leukoencephalopathy (5 of 30 patients), cerebral hemorrhage ( 1 of 30 patients), pulmonary infection ( 1 of 30 patients), suicide ( 1 of 30 patients), and multiple intracranial disease (1 of 30 patients).

\section{Discussion}

HGG is a disease that mainly grows from the site of origin and can spread throughout the brain. It can invade the adjacent brain to some extent, which is invisible to the naked eye or in imaging examination, thus preventing complete oncological resection and promoting resistance to radiotherapy and chemotherapy [11]. For most patients with HGG, surgery is the first-line choice; however, it is hard for neurosurgeons to determine the extent of resection. Thus, relapses of HGG constitute the setback for surgeries [4, 12], which is always a difficult subject for doctors.

Therapies for patients with progressive or recurrent HGG remain a controversial subject. Most patients have already lost the chance for repeated surgery after glioma relapse, and radiotherapy and/or chemotherapy may be the only treatment options available. However, not all patients accept radiotherapy and/or chemotherapy treatment due to the efficacy, time, costs, side effects, etc. The median OS of patients with glioblastoma after surgery treated with radiotherapy and adjuvant temozolomide was only 14.6 months, and for radiology alone, it was 12.1 months [13]. Usually, patients face increased intracranial pressure early after radiotherapy as well as late radiation effects, such as true radionecrosis, leukoencephalopathy syndrome, lacunar infarcts, brain parenchymal calcifications, Moyamoya syndrome, 
Table 2 Univariate analysis for OS and PFS

\begin{tabular}{|c|c|c|c|c|}
\hline \multicolumn{5}{|c|}{ Univariate Analysis } \\
\hline & OS & & PFS & \\
\hline Characteristics & Median (mo) & $\begin{array}{l}\mathrm{p} \\
\text { Values }^{\mathrm{b}}\end{array}$ & Median (mo) & $\begin{array}{l}\mathrm{p} \\
\text { Values }\end{array}$ \\
\hline Group & & 0.751 & & 0.203 \\
\hline $\mathrm{SI}$ & $\begin{array}{l}22(14.50- \\
29.50)\end{array}$ & & $8(5.47-10.53)$ & \\
\hline SRCl & $\begin{array}{l}21(18.89- \\
23.11)\end{array}$ & & $7(4.74-9.26)$ & \\
\hline Age & & 0.006 & & 0.029 \\
\hline$\geq 60$ & $\begin{array}{l}22(20.36- \\
23.64)\end{array}$ & & $8(6.81-9.19)$ & \\
\hline$<60$ & $\begin{array}{l}17(11.82- \\
22.18)\end{array}$ & & $4(2.06-5.94)$ & \\
\hline KPS & & $<0.001$ & & $<0.001$ \\
\hline $90-100$ & $\begin{array}{l}35(23.63- \\
46.38)\end{array}$ & & $\begin{array}{l}12(8.80- \\
15.20)\end{array}$ & \\
\hline$\leq 80$ & $\begin{array}{l}16(14.17- \\
17.84)\end{array}$ & & $6(5.14-6.86)$ & \\
\hline Tumor Position & & & & 0.074 \\
\hline Frontal lobe & & & $\begin{array}{l}10(7.31- \\
12.69)\end{array}$ & \\
\hline Occipital lobe & & & 13 & \\
\hline Parietal lobe & & & $8(0.00-28.58)$ & \\
\hline $\begin{array}{l}\text { Temporal } \\
\text { lobe }\end{array}$ & & & $7(4.30-9.70)$ & \\
\hline multi-lobe & & & $6(5.32-6.68)$ & \\
\hline $\begin{array}{l}\text { tumor } \\
\text { diameter }\end{array}$ & & & & 0.015 \\
\hline$\geq 5 \mathrm{~cm}$ & & & $9(6.99-11.01)$ & \\
\hline$<5 \mathrm{~cm}$ & & & $6(5.24-6.76)$ & \\
\hline Vertigo & & & & 0.074 \\
\hline NO & & & $8(6.70-9.30)$ & \\
\hline Yes & & & $5(3.64-6.36)$ & \\
\hline Nausea & & & & 0.040 \\
\hline No & & & $9(6.06-11.94)$ & \\
\hline Yes & & & $6(4.36-7.64)$ & \\
\hline Vomit & & & & 0.078 \\
\hline No & & & $8(6.38-9.62)$ & \\
\hline Yes & & & $6(4.33-7.67)$ & \\
\hline
\end{tabular}

Note.-Date in parentheses are $95 \% \mathrm{Cl}$

bog-rank test was used

telangiectasias, and enhancing whiter matter abnormalities [13, 14]. Moreover, attempts to improve the survival of HGG patients with increased radiation doses have failed [15].

Iodine-125 seeds are emerging as a safe, effective and minimally invasive method applied in various tumors [16-20]. Several studies have proven that iodine-125 implantation could improve the survival of patients with
Table 3 Multivariate analysis for OS and PFS

\begin{tabular}{|c|c|c|c|c|}
\hline \multicolumn{5}{|c|}{ Multivariate Analysis } \\
\hline Characteristics & OS & & PFS & \\
\hline & Hazard Ratio & $p$ Values $^{c}$ & Hazard Ratio & p Values ${ }^{c}$ \\
\hline Age & & 0.016 & & $<0.001$ \\
\hline$\geq 60$ & 1 & & 1 & \\
\hline$<60$ & $2.70(1.21-6.03)$ & & $4.96(2.10-11.7)$ & \\
\hline KPS & & $<0.001$ & & 0.047 \\
\hline $90-100$ & 1 & & 1 & \\
\hline$\leq 80$ & $4.42(1.94-10.07)$ & & $2.92(1.40-6.09)$ & \\
\hline Histology & & & & 0.008 \\
\hline WHO 3 & & & 1 & \\
\hline $\mathrm{WHO} 4$ & & & $3.99(1.43-11.14)$ & \\
\hline
\end{tabular}

Note.-Date in parentheses are $95 \% \mathrm{Cl}$

${ }^{\mathrm{c} C o x}$ proportional hazards regression analysis was used

gliomas [5, 8-10, 21-23]. Especially in China, as more people become aware of this therapeutic method, they tend to prefer it because it is minimally invasive. Iodine125 seeds are implanted accurately into the exact site of the tumor, which could give a much higher radiation dose and cover a larger radiation area on the oncological border with confirmed safety. Additionally, with permanent implantation, iodine- 125 seeds could play continuous roles within the tumor, with the continuous release of low-dose $\gamma$ rays, which is different from EBRT; iodine-125 brachytherapy administers a higher PD and therapeutic target [24]. Iodine-125 implantation has mostly been used as a salvage therapy after radiotherapy and/or chemotherapy for progressive or recurrent patients with gliomas. However, no evidence has shown whether iodine-125 brachytherapy could be used as a primary therapeutic method for patients with progressive or recurrent HGG after gross total resection. Moreover, whether the survival of patients who received iodine-125 seed implantation without radiotherapy and/ or chemotherapy is affected needs to be explored.

In this study, we analyzed 58 patients from 16 hospitals with progressive or recurrent HGG after gross total resection. No significant differences were found between the two groups in OS or PFS. These results indicated that patients may undergo iodine-125 implantation after gross total resection without radiotherapy and/or adjuvant chemotherapy, since it had no effects on their survival or on the relapse of glioma. Based on our experiences, the border of the PTV in this study was 10 $\mathrm{mm}$ beyond the gross target volume (GTV), different from the previously reported $5 \mathrm{~mm}$ [6], while safety and efficacy were confirmed.

The KPS scores of patients remained stable before and after implantation within 1 year. Most patients died 1 year after the implantation of iodine- 125 seeds; thus, the 
follow-up KPS score 1 year after iodine-125 implantation did not reflect the exact quality of life of the patients.

In contrast to that in other previous studies $[6,8-10]$, we permanently implanted iodine- 125 seeds with a flat needle, effectively avoiding damage to brain vessels and tissues. Safety was confirmed, no surgery-related fatal events happened, and the temporary morbidity rate was $11.9 \%$ perioperatively. The condition of patients with heavier brain edema improved a few months after the implantation with dehydration treatment, and selfabsorption of the cerebral hemorrhage was almost complete approximately 15 days with the conservation treatment. Based on our experience with more than 400 cases of iodine-125 implantation into brain tumors, we also included 30 patients with tumor diameters beyond $5 \mathrm{~cm}$ in this study. Heavier cerebral edema happened in 2 of the 30 patients with tumor diameters beyond $5 \mathrm{~cm}$, and cerebral hemorrhage occurred in 2 of the 30 patients with tumor diameters beyond $5 \mathrm{~cm}$. The complications improved days later with conservation treatment. Thus, we believe that the implantation of iodine- 125 seeds in patients with progressive or recurrent HGG with tumor diameters beyond $5 \mathrm{~cm}$ is safe. In the present study, both age and KPS were independent prognostic factors for OS and PFS, which was in line with the findings of previous studies [10, 25].

The results indicated that patients who were younger or had higher KPS scores survived for a longer time after multimodality therapy. Moreover, histology was thought to be an independent prognostic factor for PFS. Glioma relapse happened more often in patients who were diagnosed with WHO grade IV gliomas. Additionally, there are limitations in this study. The sample size analyzed in this study was not large enough. Only patients who underwent gross total resection were analyzed, and patients who underwent subtotal resection or biopsy were not included, so further studies are needed.

\section{Conclusions}

Altogether, the present study showed that allowing for costs, fees and side effects, for progressive or recurrent HGG patients after gross total resection who have lost the chance for repeat surgery, iodine-125 brachytherapy could be an effective therapeutic method even without radiotherapy and/or chemotherapy.

\footnotetext{
Abbreviations

HGGs: High-grade gliomas; OS: Overall survival; PFS: Progression-free survival; KPS: Karnofsky Performance Status; EBRT: External beam radiotherapy; $C T$ : Computed tomography; MRI: Magnetic resonance imaging; PD: Prescribed dose; GTV: Gross target volume
}

\section{Authors' contributions}

CXW conducted all experiments, integrated data, edited figures, and wrote the manuscript; SFL and LJP help with the data analysis. KXZ,WL, HZ, YL and PSL provided essential assistance; $\mathrm{XKH}$ directed this study, designed the research and gave key advices. All authors have read and approved the manuscript.

\section{Funding}

This work was supported by the the National Science Foundation for Youths of China (NO. 81901800). The funders played no role in a) the design of the study; b) the collection, analysis, and interpretation of the data; and c) writing of the manuscript.

\section{Availability of data and materials}

The datasets used and/or analysed during the current study are available from the corresponding author on reasonable request.

\section{Ethics approval and consent to participate}

The study was approved by the Institutional Ethics Review Boards of the Affiliated Hospital of Qingdao University with the requirement of informed consent waived (Reference number: QYFY WZLL 25802).

\section{Consent for publication}

Not applicable.

\section{Competing interests}

None.

\section{Author details}

${ }^{1}$ Department of the Interventional Medical Center, the Affiliated Hospital of Qingdao University, \#1677 Wutaishan Road, Qingdao 266000, Shandong, China. ${ }^{2}$ Department of Clinical Laboratory, the Affiliated Hospital of Qingdao University, Qingdao, China. ${ }^{3}$ Department of Oncology, Tengzhou Central People's Hospital, Zaozhuang 277500, Shandon, China. ${ }^{4}$ Jiangsu Key Laboratory of Molecular and Functional Imaging, Department of Radiology, Zhongda Hospital, Medical School of Southeast University, Nanjing 210009, China.

Received: 7 January 2020 Accepted: 17 June 2020

Published online: 24 June 2020

\section{References}

1. Wen PY, Reardon DA. Progress in glioma diagnosis, classification and treatment. Nat Rev Neurol. 2016;12(2):69-70.

2. Ohgaki $\mathrm{H}$, Kleihues P. Population-based studies on incidence, survival rates, and genetic alterations in astrocytic and oligodendroglial gliomas. J Neuropathol Exp Neurol. 2005:64(6):479-89.

3. Kohler BA, Ward E, McCarthy BJ, Schymura MJ, Ries LA, Eheman C, Jemal A, Anderson RN, Ajani UA, Edwards BK. Annual report to the nation on the status of cancer, 1975-2007, featuring tumors of the brain and other nervous system. J Natl Cancer Inst. 2011;103(9):714-36.

4. Eyüpoglu IY, Buchfelder M, Savaskan NE. Surgical resection of malignant gliomas-role in optimizing patient outcome. Nat Rev Neurol. 2013;9(3): $141-51$

5. Hu X, Qiu H, Zhang L, Zhang W, Ma Y, Qiao Z, Chen D, Han J, Duan G, Zhang F. Recurrent gliomas. Cancer Biology \& Therapy. 2014;13(10):840-7.

6. Wen PY, lii EA, Black PM, Fine HA, Riese N, Levin JM, Norman Coleman C, Loeffler JS. Long term results of stereotactic brachytherapy used in the initial treatment of patients with glioblastomas. Cancer. 1994;73(12):3029-36.

7. Larson DA, Suplica JM, Chang SM, Lamborn KR, McDermott MW, Sneed PK, Prados MD, Wara WM, Nicholas MK, Berger MS. Permanent iodine 125 brachytherapy in patients with progressive or recurrent glioblastoma multiforme. Neuro-oncology. 2004;6(2):119-26.

8. Suchorska B, Ruge M, Treuer H, Sturm V, Voges J. Stereotactic brachytherapy of low-grade cerebral glioma after tumor resection. Neuro-oncology. 2011; 13(10):1133-42.

9. Ruge MI, Kickingereder P, Grau S, Dorn F, Galldiks N, Treuer H, Sturm V. Stereotactic iodine-125 brachytherapy for the treatment of WHO grades II and III gliomas located in the central sulcus region. Neuro-oncology. 2013 15(12):1721-31. 
10. Suchorska B, Hamisch C, Treuer H, Mahnkopf K, Lehrke RE, Kocher M, Ruge MI, Voges J. Stereotactic brachytherapy using iodine 125 seeds for the treatment of primary and recurrent anaplastic glioma $\mathrm{WHO}^{\circ} \mathrm{III}$. J NeuroOncol. 2016;130(1):123-31.

11. Hochberg FH, Pruitt A. Assumptions in the radiotherapy of glioblastoma. Neurology. 1980;30(9):907.

12. Kubben PL, Postma AA, Kessels AGH, van Overbeeke JJ, van Santbrink H. Intraobserver and Interobserver agreement in volumetric assessment of Glioblastoma Multiforme resection. Neurosurgery. 2010;67(5):1329-34.

13. Brandsma D, Stalpers L, Taal W, Sminia P, van den Bent MJ. Clinical features, mechanisms, and management of pseudoprogression in malignant gliomas. The Lancet Oncology. 2008;9(5):453-61.

14. Belka C, Budach W, Kortmann R, Bamberg M. Radiation induced CNS toxicity-molecular and cellular mechanisms. Br J Cancer. 2001;85(9):1233.

15. Nieder C, Andratschke N, Wiedenmann N, Busch R, Grosu AL, Molls M. Radiotherapy for high-grade gliomas. Does altered fractionation improve the outcome? Strahlenther Onkol. 2004;180(7):401-7.

16. Kickingereder P, Hamisch C, Suchorska B, Galldiks N, Visser-Vandewalle V, Goldbrunner R, Kocher M, Treuer H, Voges J, Ruge MI. Low-dose rate stereotactic iodine-125 brachytherapy for the treatment of inoperable primary and recurrent glioblastoma: single-center experience with 201 cases. J Neuro-Oncol. 2014;120(3):615-23.

17. Yu Y-h. Wei C-y, Qin Q-h, Mo Q-g, Huang Z, Lian B: efficacy of lodine-125 seed implantation in Locoregionally recurrent and Unresectable breast Cancer: a retrospective study. Pathology \& Oncology Research. 2017;25(1): 327-32.

18. He Y, Li L, Liu J, Zhang X. lodine-125 seed brachytherapy inhibits non-small cell lung cancer by suppressing epithelial-mesenchymal transition. Brachytherapy. 2018;17(4):696-701.

19. Chen K, Chen G, Wang H, Li H, Xiao J, Duan X, He J, He K, Xiang G. Increased survival in hepatocellular carcinoma with iodine-125 implantation plus radiofrequency ablation: a prospective randomized controlled trial. J Hepatol. 2014;61(6):1304-11.

20. Zhang W, Li J, Li R, Zhang Y, Han M, Ma W. Efficacy and safety of iodine-125 radioactive seeds brachytherapy for advanced non-small cell lung cancer-a meta-analysis. Brachytherapy. 2018;17(2):439-48.

21. Ruge MI, Simon T, Suchorska B, Lehrke R, Hamisch C, Koerber F, Maarouf M, Treuer H, Berthold F, Sturm V, et al. Stereotactic brachytherapy with iodine125 seeds for the treatment of inoperable low-grade gliomas in children: long-term outcome. J Clin Oncol. 2011;29(31):4151-9.

22. Nachbichler SB, Kreth F-W: Brachytherapy of Intracranial Gliomas. In: Intracranial Gliomas Part II - Adjuvant Therapy. edn.; 2018: 72-86.

23. Ruge Ml, Kickingereder P, Simon T, Treuer H, Sturm V. Stereotactic iodine125 brachytherapy for treatment of inoperable focal brainstem gliomas of WHO grades I and II: feasibility and long-term outcome. J Neuro-Oncol. 2012;109(2):273-83.

24. Wang Z, Lu J, Liu L, Liu T, Chen K, Liu F, Huang G. Clinical application of CTguided (125) I seed interstitial implantation for local recurrent rectal carcinoma. Radiat Oncol. 2011;6:138.

25. Nuno M, Birch K, Mukherjee D, Sarmiento JM, Black KL, Patil CG. Survival and prognostic factors of anaplastic gliomas. Neurosurgery. 2013;73(3):458-65 quiz 465.

\section{Publisher's Note}

Springer Nature remains neutral with regard to jurisdictional claims in published maps and institutional affiliations.

Ready to submit your research? Choose BMC and benefit from:
- fast, convenient online submission
- thorough peer review by experienced researchers in your field
- rapid publication on acceptance
- support for research data, including large and complex data types
- gold Open Access which fosters wider collaboration and increased citations
- maximum visibility for your research: over 100M website views per year
At BMC, research is always in progress.
Learn more biomedcentral.com/submissions

